\title{
Use of Mini-Implant Anchorage For Second Molar Mesialization: Comprehensive Approach For Treatment Efficiency Analysis
}

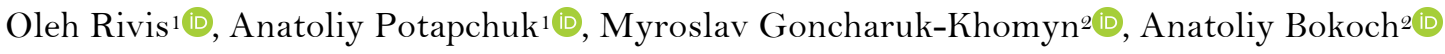

${ }^{1}$ Department of Postgraduate Dental Education, Uzhhorod National University, Uzhhorod, Ukraine.

${ }^{2}$ Department of Prosthetic Dentistry, Uzhhorod National University, Uzhhorod, Ukraine.

Author to whom correspondence should be addressed: Myroslav Goncharuk-Khomyn, Department of Prosthetic Dentistry, Uzhhorod National University, Universitetska 16/a st, Uzhhorod, Ukraine. 88000. Phone: 0991212813. E-mail: myroslav.goncharuk-khomyn@uzhnu.edu.ua.

Academic Editors: Alessandro Leite Cavalcanti and Wilton Wilney Nascimento Padilha

Received: 24 September 2019 / Accepted: 16 November 2019 / Published: 21 November 2019

How to cite this article: Rivis O, Potapchuk A, Goncharuk-Khomyn M, Bokoch A. Use of mini-implant anchorage for
second molar mesialization: comprehensive approach for treatment efficiency analysis. Pesqui Bras Odontopediatria Clín
Integr. 2020; 20:e5262. https://doi.org/10.1590/pboci.2020.018

\begin{abstract}
Objective: To approbate the complex approach for assessment of second molar mesialization outcomes with the use of orthodontic mini-implants. Material and Methods: The sample consisted of 62 patients, divided into study $(\mathrm{n}=32)$ and control group $(\mathrm{n}=30)$. Mesialization procedure in the study group was conducted with the use of braces system and orthodontic mini-implants as additional anchorage devices, while in control group mesialization was provided only with the use of the brace system. Dynamic registration of bone level changes and the entire range of tooth movement were carried out on digital orthopantomograms obtained with the use of Planmeca ProMax 2D. Results: Findings of orthopantomographic (OPG) analysis have shown that cases of second molar mesialization with the use of mini-implants as temporary anchorage characterized with more stable conditions of bone levels around displaced teeth compare to cases, where mesialization was provided only with the use of braces systems without any additional anchorage. The terms of treatment in the study group with the use of dental mini-implants as the anchorage was reduced by $8.8 \pm 0.12$ months compared to the control group $(\mathrm{p}<0.05)$. Conclusion: The use of orthodontic miniimplants as anchorage constructions during the mesialization of the mandibular second molars contributes to the reduction of treatment duration and support the more prognostic movement of teeth, that does not provoke significant pathological changes in the levels of the surrounded alveolar ridge and minimize the risk of associated periodontal complication occurrence.
\end{abstract}

Keywords: Dental Implants; Molar; Mesial Movement of Teeth; Radiography, Dental, Digital. 


\section{Introduction}

Mesialization of posterior teeth for edentulous space closing characterized by the different levels of clinical difficulty due to the initial conditions of bite abnormalities [1-3]. Realization of such procedures without using any additional anchorage outlined by possible non-prognostic undesired effects. Previous results obtained during in vivo and in vitro studies suggested that after tooth movement in the form of mesialization there is a chance of periodontal support loss, but except that adverse effect of mesialization procedure could be associated with the rotation of mesialized tooth, its extrusion and non-preferable changes in occlusal force distribution [4-9].

Mesialization procedure of molars with the use of anterior dentition or premolars as an anchorage was found to be associated with the middle line deviations, posterior displacement of surrounding soft tissue, and changes of visual profile $[6,8,9]$. Because of these problems, researches proposed a variety of methods not only for the treatment of such complications but also for their prevention during controlled orthodontic tooth movement. That is why argued mesialization procedure due to the results of previous studies in some cases should be provided by the model of rectangular archwires, which helps to control changes of torque, inclination, and rotation of teeth [5-7].

The use of orthodontic mini-implants also provides conditions for the guided tooth movement and traction of desired posterior jaw segments [10-12]. Previous authors informed a $91 \%$ success rate of temporary anchorage devices in the form of palatally installed implants [13-15]. Researches also noted that the stability of such anchorage by the cephalometric analysis is sometimes underestimated, which can be caused by the inaccurate identification of landmark points, while clinically under orthodontic load, these constructions remain stable in alveolar bone [14-16].

The use of direct anchorage in the form of installed mini-implant that is connected to the teeth requiring horizontal movement causes low levels of strains on anchor unit comparing to the results that were registered during indirect anchorage with one or two anchor teeth [17].

But there is still a deficiency of objective approach for the complex evaluation of mesialization procedure efficiency with the use of orthodontic implants considering the range of tooth movement, levels of alveolar bone reduction and changes in tooth inclination after obtaining desired tooth position at the mandibular alveolar ridge, which is characterized by narrow profile and more compact structure.

That is why the objective of this study was to approbate the complex approach for assessment of molar mesialization outcomes with the use of orthodontic mini-implants by means of such parameters, as tooth inclination, bone levels changes, and duration of treatment.

\section{Material and Methods}

\section{Study Design and Sample}

The primary stage of the research suggested the formation of study and control samples among orthodontic patients with bite abnormalities, considering the possibility of second molar mesialization as an acceptable and predictively effective treatment option.

The criteria for further inclusion of patient into the study or control groups were as follows: 1) the presence of bite alteration symptoms at the time of the patient's referral to the clinic in the form of mandibular partial adentia at first molar region; 2) the absence of any associational somatopathy or adjoining contraindications that would restrain possibility for orthodontic treatment in the form of second molar mesialization; 3) the possibility for providing remaining second molar mesialization by means of its structural 
integrity (including absence of any alteration of second molar's structure that was suggested for mesialization); 4) age of patients above 18 years (for possibility to provide personal agreement on proposed treatment); 5) agreement on providing second molar mesialization procedure after full consultation and signing form of informational consent.

Exclusion criteria were as follows: 1) age of the patient below 18 years old; 2) compromised the structural condition of second molar requiring mesialization; 3) presence of somatopathologies that could restrict possibilities of effective orthodontic treatment; 4) personal refusal to take part in the proposed survey. A sample of 62 patients was formed, who were randomly distributed among the study group consisted of 32 patients, and the control group consisted of 30 patients.

Clinical Procedures

Mesialization procedure in the study group was conducted with the use of brace system and orthodontic mini-implant (OMG, Ukraine) as an additional anchorage device, while in control group mesialization was provided only with the use of brace system [18-20]. The installation of mini-implant was carried due to the relevant guidelines considering the individual characteristics of each clinical situation [19].

Dynamic registration of bone level changes and absolute range of tooth movement was carried out on digital orthopantomograms, obtained for every patient before and after treatment with the use of Planmeca ProMax 2D scanner (Planmeca Oy, Helsinki, Finland) on the base of Orthodontic Dental Clinic and Uzhhorod National University (Uzhhorod, Ukraine) (Figure 1).

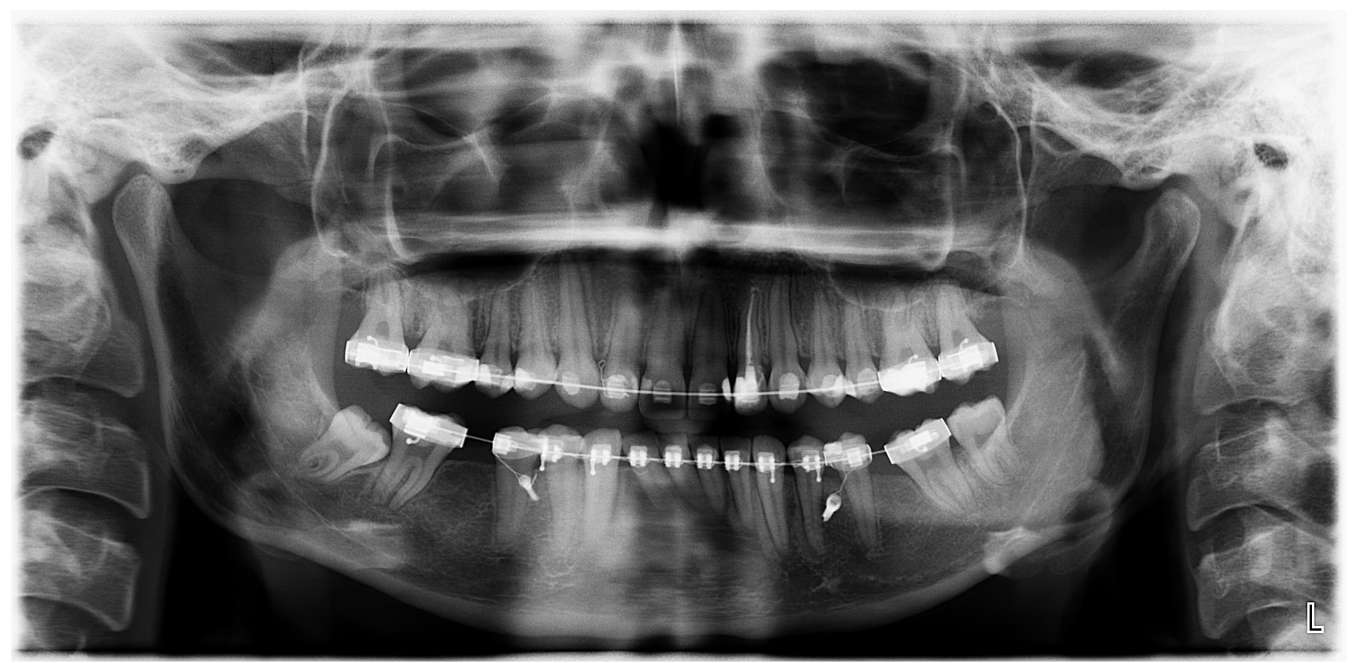

Figure 1. Orthopantomogram of the patient after mini-implants installation.

In order to enhance the objectification of the OPG results and standardize the original parameters of digital images during X-ray diagnostics, the doctor provided strict positioning of patients in accordance with all necessary anatomical guidelines. Received images were further calibrated in a horizontal plane drawn between the projections of mental foramen centers.

Original algorithm of graphical analyses of OPG included next steps: 1) designation of the basic control points A (left) and B (right) in the centers of the visible projection of the right and left mental foramens respectively and drawing of $\mathrm{AB}$ line between them; 2) marking of point $\mathrm{O}$ as the midline of $\mathrm{AB}$ horizontal line; 3) mapping straight tangent lines from point A or B to mesial and distal most coronal aspects of alveolar bone contacted with the second molar suggested for mesialization before the treatment, forming lines AM (mesial 
right) and $\mathrm{AD}$ (distal right) or $\mathrm{BM}$ (mesial left) and $\mathrm{BD}$ (distal left); 4) registering absolute distances in millimeters from point A (or point B) to the mesial and distal part of the second molar; 5) mapping straight tangent lines from point $\mathrm{O}$ to mesial and distal most coronal aspects of alveolar bone contacted with the second molar suggested for mesialization before the treatment forming lines OD (distal) and OM (mesial) (mapping tangent line from points $\mathrm{A}$ or $\mathrm{B}$ and also from point $\mathrm{O}$ argumented by the discrepancies of OPG images and tryouts for their minimization); 6) registering absolute distances in millimeters from point $\mathrm{O}$ to the mesial of distal part of the second molar; 7) repeat steps 1-6 after the treatment; 8) calculate the length differences of each tangent line drawn from points $\mathrm{A}$ or $\mathrm{B}$ and from point $\mathrm{O}$.

Each measurement was repeated five times to find out the range of measuring variation and minimize the level of processing bias by finding mean value. The algorithm mentioned above was adapted from the original technique and dedicated to the dynamic registration of bone tissue changes after iatrogenic interventions (Figure 2) [21,22].

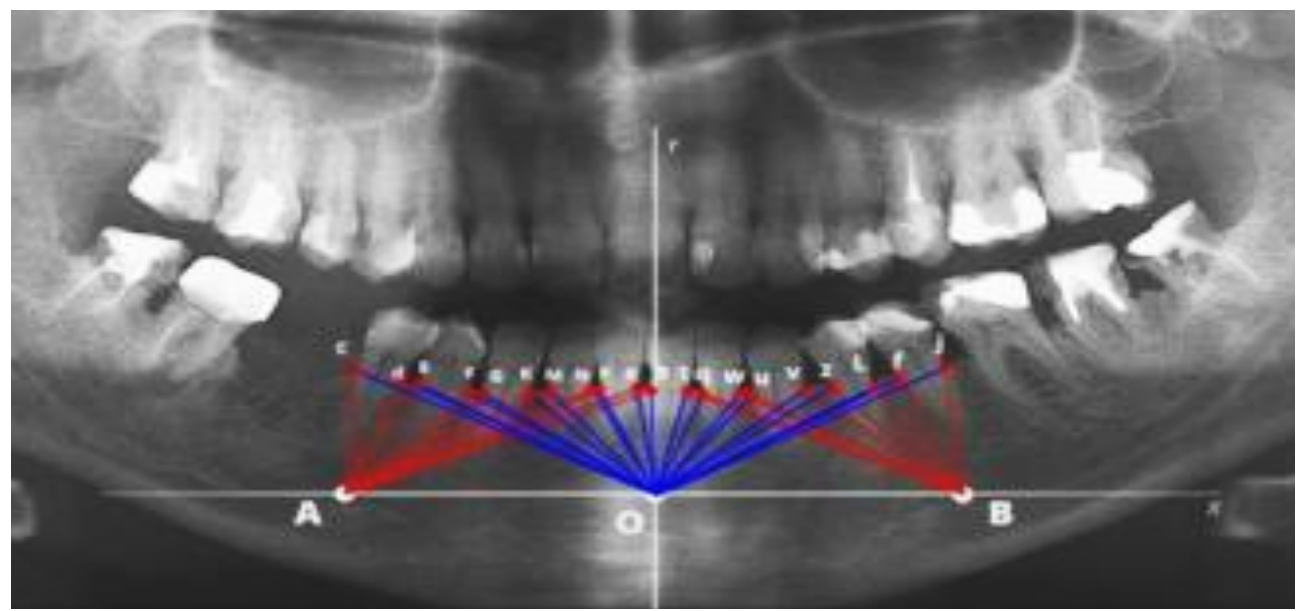

Figure 2. Visualization of the original graphical model for OPG-analysis (modification of such model described above was used during the study) $[21,22]$.

Such an approach allows verifying the absolute range of bone level reduction around mesialized teeth during their movement. Graphical analysis of OPGs was carried out in GIMP 2.10 software (The GIMP Development Team) after their export from Planmeca Romexis Viewer [23].

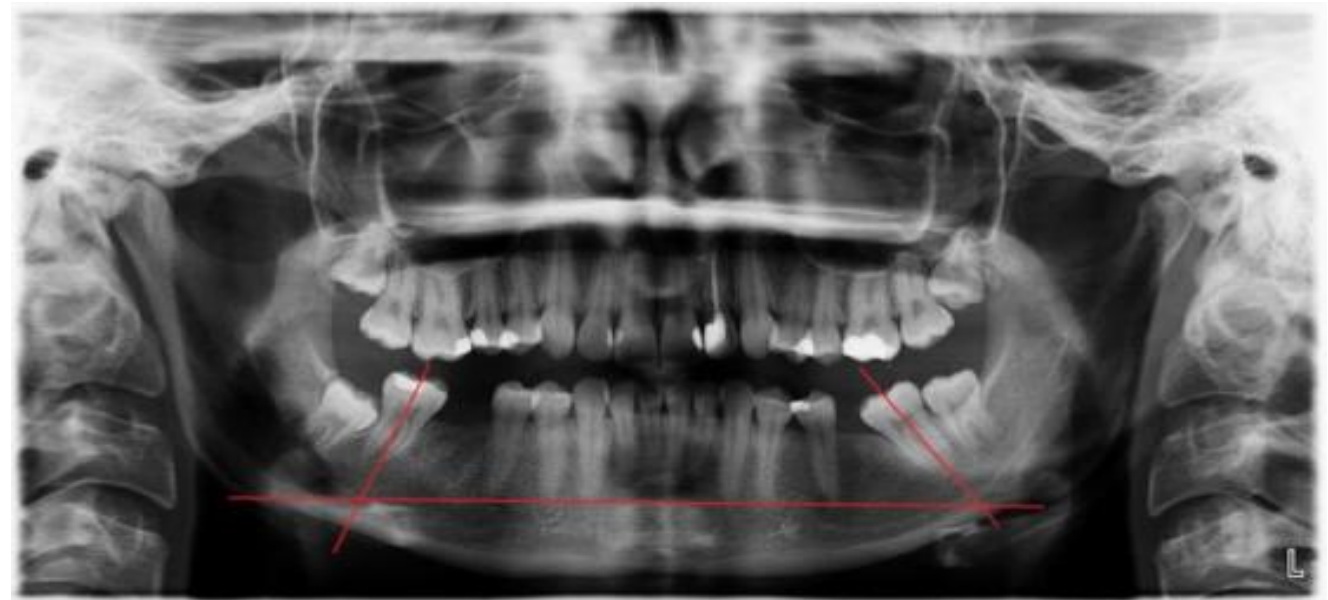

Figure 3. Principle of estimation tooth inclination by Ursi technique [24] 
Angulation of teeth was evaluated with the technique proposed previously, which envisaged the determination of tooth longitudinal axis inclination corresponding to the horizontal line drawn through the centers of the mental foramen on both sides of the mandible (Figure 3) [24]. The longitudinal axis of the tooth was determined by a line passing through the middle of the occlusal surface to the furcation point.

Each patient was diagnosed for the magnitude of the required second molar mesialization on control and diagnostic cast models.

\section{Data Analysis}

To estimate the efficiency differences between study and control groups, the mean values of each evaluation criteria were used. Bivariate correlation between the range of desirable mesialization and parameters of final tooth position, angulation, and time of treatment was evaluated by correlation coefficient (Pearson's r) and checked by statistical hypothesis testing [25-27]. Linear regression analysis was assigned for modeling the interaction between such dependent variables as inclination, range of movement and time of treatment and independent variables, such as age and gender. All statistical data processing was held in Microsoft Excel software (Microsoft Office 2016, Microsoft).

\section{Results}

The study group consisted of 32 individuals (18 female/56.3\% and 14 male/43.7\%) aged 18-25 years (23.15 \pm 1.19 years). The control group included 30 patients (19 female/63.3\% and 11 male/36.7\%) aged 19-25 years $(23.07 \pm 1.02$ years). There was no association between gender and age $(\mathrm{p}>0.05)$.

The study group included 22 (68.8\%) patients with Angle's I class of bite abnormalities, 9 (28.1\%) patients with Angle's II class of bite abnormalities and 1 (3.1\%) patient with Angle III class of bite abnormalities. Control group consisted of 21 (70\%), 8 (26.7\%) and 1 (3.3\%) patients of each Angle's class respectively. In the study group, $21(65.6 \%)$ patients had a one-sided edentulous defect in the area of the first permanent lower molar and $11(34.4 \%)$ patients had a bilateral tooth row defect at the same region. Thus, in the study group, 43 mini-implants were installed and 43 permanent second molars were mesialized. In the control group, $20(66.7 \%)$ patients had one-sided tooth row defect in the area of the first permanent lower molar and $10(33.3 \%)$ patients had a bilateral defect in the same area. Thus, in the control group, 40 permanent second molars were mesialized just with the use of a brace system.

Exact results of OPG-analysis before and after treatment are represented in Table 1. Absolute differences of the tangent lines length registered before and after treatment were greater in the control group compared to the study group, but a statistically significant difference between both groups was noted only for the $\Delta O M$ parameter $(\mathrm{p}<0.05)$. Such findings are showing that cases of second molar mesialization with the use of mini-implant as temporary anchorage characterized with the more stable condition of bone levels around displaced teeth compare to cases, where mesialization was provided only with the use of braces systems without any addition anchorage.

During the analysis of tooth angulation among the patients of two groups the following results were obtained: the magnitude of the mesio-distal inclination of second molars requiring mesialization in the study group ranged $65.2-69.23^{\circ}$ (mean value $66.48^{\circ} \pm 0.74^{\circ}$ ), and in control group ranged $56.72-69.81^{\circ}$ (mean value $\left.66.33^{\circ} \pm 0.72^{\circ}\right)$ 
Table 1. Summary of referent lines lengths changes during OPG analysis.

\begin{tabular}{clcccc}
\hline \multicolumn{1}{c}{ Groups } & \multicolumn{2}{c}{ Treatment } & \multicolumn{4}{c}{ OPG Analysis $(\mathbf{m m} \pm \mathbf{m m})$} \\
& & $\mathrm{AM} / \mathrm{BM}$ & $\mathrm{AD} / \mathrm{BD}$ & $\mathrm{OM}$ & OD \\
\hline Study & Before & $11.36 \pm 0.34$ & $12.28 \pm 0.37$ & $23.19 \pm 0.69$ & $25.09 \pm 0.71$ \\
& After & $9.18 \pm 0.46$ & $9.93 \pm 0.43$ & $20.98 \pm 1.07$ & $22.68 \pm 1.0$ \\
& Difference & $\Delta \mathrm{AM} / \mathrm{BM}$ & $\Delta \mathrm{AD} / \mathrm{BD}$ & $\Delta \mathrm{OM}$ & $\Delta \mathrm{OD}$ \\
& & $2.17 \pm 0.06$ & $2.34 \pm 0.06$ & $2.24 \pm 0.09$ & $2.43 \pm 0.08$ \\
Control & Before & $10.89 \pm 0.34$ & $11.41 \pm 0.35$ & $23.19 \pm 0.81$ & $23.36 \pm 0.75$ \\
& After & $8.50 \pm 0.22$ & $8.79 \pm 0.27$ & $19.74 \pm 0.66$ & $20.42 \pm 0.64$ \\
& Difference & $\Delta \mathrm{AM} / \mathrm{BM}$ & $\Delta \mathrm{AD} / \mathrm{BD}$ & $\Delta \mathrm{OM}$ & $\Delta \mathrm{OD}$ \\
& & $2.59 \pm 0.09$ & $2.62 \pm 0.10$ & $3.44 \pm 0.18$ & $2.98 \pm 0.10$ \\
\hline
\end{tabular}

AM/BM: Distances from points A and B (projections of mental foramen on the right and left) to mesial most coronal aspects of alveolar bone contacted with the molar suggested for mesialization; AD/BD: Distances from points A and B (projections of mental foramen on the right and left) to distal most coronal aspects of alveolar bone contacted with the molar suggested for mesialization; OM: Distance from point $\mathrm{O}$ (midpoint of the distance between points $\mathrm{A}$ and $\mathrm{B}$ ) to mesial most coronal aspects of alveolar bone contacted with the molar suggested for mesialization; OD: Distance from point $\mathrm{O}$ (midpoint of the distance between points A and B) to distal most coronal aspects of alveolar bone contacted with the molar suggested for mesialization.

As a result of the carried out corpus displacement of teeth using the mini-implant as an anchorage the final range of the inclination parameter among patients of study group at the end of the treatment was 69.54$73.72^{\circ}$ (mean value $71.82 \pm 0.23^{\circ}$ ), while in the control group the same parameter ranged in $68.42-72.11^{\circ}$ (mean value $71.49 \pm 0.25^{\circ}$ ). Also among patients of control group a loss of mandibular incisor inclination was found in $5(16.7 \%)$ patients, distal inclination of premolars was noted in 4 (13.3\%) patients, distal rotation of premolars was registered in $2(6.7 \%)$ patients and combination of several complications was found among 2 $(6.7 \%)$ patients. Such results could be categorized as complications of using natural dentition for anchorage during the procedure of molar mesialization.

According to the results presented above, 93.7\% ( $\mathrm{n}=30)$ of the study group and $86.7 \%(\mathrm{n}=26)$ of the control group achieved the successful treatment results. No statistically approved linear or curvilinear association were found between parameters of age or gender and facts of reached level of second molar mesialization or facts of registered complications during all period of treatment $(\mathrm{p}>0.05)$.

The terms of complex treatment of dental patients with the need of molar mesialization differed among study and control group: in study group median duration of treatment time was $2.19 \pm 0.05$ years, while in the control group, this parameter was $2.92 \pm 0.04$ years. Thus, the terms of treatment in the study group with the use of dental mini-implants as the anchorage was reduced by $8.8 \pm 0.12$ months compared to the control group $(\mathrm{p}<0.05)$.

\section{Discussion}

In a previous study, orthodontic tooth movement in the form of mesialization was associated with the active bone remodeling, which was validated by electron-probe microanalysis and growing of strontium amount around shifted tooth [28]. Even though the research was provided on the rodent model, it has shown the total stability of mini-implant as an anchorage device and the most active tooth displacement during the first month of force applied. In terms of apical root resorption due to the results of the split-mouth study, space closure of the edentulous molars region through the mesialization treatment option could be considered as clinically safe [9]. The authors also mentioned the problem of deficiency for the objective method that can be used for further force selection and morphological changes evaluation during orthodontic tooth movement in the direction to mini-implant stable position. 
During the research of orthodontic microimplants by the results of panoramic radiographs, the authors found out that the length parameter of the anchorage device had a statistically important influence on the value of orthodontic implant success [29]. Intrabone implant anchorage positioned more apically and with a lower level of angulation demonstrated the highest results of success. In our research, we positioned all miniimplants between premolars with 90-degree angulation to the bone surface. Based on previously reported results [29], such an approach of implant positioning could be the explanation of the fact that none of the installed implants was lost. The age parameter has not played any statistical role in the success rate of used mini-implants $(\mathrm{p}>0.05)$. Nevertheless, in other researches, the higher success rate of orthodontic implants was associated with adult age compare to the data obtained among adolescents.

The surface matching approach for quantification of mesialization molar procedure helped to identify an average of $6.3 \pm 2.6 \mathrm{~mm}$ tooth movement during the provided study [30]. The approach described in this article is somewhat similar to the principle. Even though we have not used iterative closest point algorithm on digitized models, we proposed to employ referent control points in the area of the mental foramen and midline intersection compares to which we registered absolute changes of tooth position and bone level changes.

A similar approach for the evaluation of bone changes was previously proposed [31]. The authors described the method of peri-implant bone changes registration by the geometrical model consisted of tangent lines that connected apex of the implant and the most coronal part of the peri-implant bone ridge. In this research, we proposed a method of tangent lines that connects mental foramen with distal and mesial sides of teeth and also the median line with the same coordinates. The use of double measuring systems based on two different concordant points (mental foramen and median point) helped to raise the objectivity of the proposed approach and provides a greater amount of numerical data for further statistical analysis.

Orthopantomograms characterized by some level of image discrepancies that can be caused by positioning mistakes, operational errors and calibration lapses. All the above-mentioned factors disturb the accuracy of measurements on OPG-images, which also can be minimized through the appropriate interpretation of tangent line distances drawn from two different coordinate points to the same points of interest represented on the mesial and distal part of the tooth during dynamic mesialization process [32].

The results of the theoretical analysis show that the automatic measurement of ORG-image size characterized by less variation in vertical magnification dimensions compares to horizontal [32]. That is why, in our study, we provide a calculation of the bone level changes based on line lengths drawn from mental foramen point to molar of interest. Such an approach reduces the horizontal component of the analytical model and highlights its vertical part, which some authors have attributed to less distortion. Such geometrical argumentation for the graphical analysis of OPG-results already has been described in different modalities. Nevertheless, conventional analysis of OPG in orthodontic practice remains widely used, while in many cases, such kind of diagnostics among young patients was prescribed without appropriate following of guidelines [33].

Proposed algorithm of OPG-analysis helped to register decrease in the absolute length of tangent lines mapped from the projection of mental foramen to the medial $(\Delta \mathrm{AM} / \mathrm{BM})$ and the distal $(\Delta \mathrm{AD} / \mathrm{BD})$ sides of the mesialized molar in both study and control groups, indicating directed medial displacement of the teeth that have been studied. When comparing the ratio of lengths of tangent lines from the projection of mental foramen to the medial and distal sides of the molars before and after treatment with each other $(\Delta \mathrm{OM}$ and $\Delta \mathrm{OD})$, the obtained data indicated that the processes of bone remodeling during orthodontic treatment occurs synchronously within both the medial and the distal side of the moving tooth. Similar observations were found 
during the analysis of tangent lines drawn from the midpoint $\mathrm{O}$ between mental foramen and distal/medial side of mesialized teeth, which could be served as indirect evidence of bone remodeling processes in the area of force application and tooth displacement.

During statistical analysis of the data it was noted that the initial value of molar inclination before treatment was dependent on the magnitude of the tooth row defect $(\mathrm{p}<0.05)$ : the more distal the tooth that needed mesialization was, the sharper was the angle formed by the axis of the tooth and the intermental horizontal line. However, it should be noted that the magnitude of this angle is also depended on the starting position of the tooth in the jaw, which in turn could vary from several parameters, such as the anatomical features of the tooth row or magnitude of the graphics distortion in the distal parts of the orthopantomogram.

The changes in the mesiodistal angle of the tooth inclination relative to the horizontal line drawn between mental foramen indicate that the use of orthodontic mini-implants contributes to a more prognostic corpus displacement of the teeth, providing the formation of such inclination, which is more closely related to the referent [24].

In the control group, where molar mesialization was provided by using natural dentition as an anchorage, unwanted movements of teeth were registered, which arguments the need for additional orthodontic correction of their position and provokes time elongation of orthodontic treatment.

The integral indicator of the quality of treatment must take into account the timing of rehabilitation, since the use of the mini-implants as a promising method of orthodontic correction, can reduce the total time needed for iatrogenic interventions [5-7]. On the other hand, the terms of treatment, together with the parameters of functional and aesthetic restorations, affect the patient's satisfaction criterion due to the chosen appropriate rehabilitation algorithm. In our opinion, the reduction in terms of treatment in the study group was reached due to the fact of more controlled corpus tooth displacement without any undesirable movements, such as inappropriate inclination, rotation or loss of periodontal support. This helps to resume that miniimplants installed in the alveolar ridge provide a reliable skeletal resistance and minimize the risk of possible undesirable tooth displacement.

In the presented study, we propose a new integral approach for the efficiency evaluation of different orthodontic treatment modalities that include tooth movement phase. The complex algorithm includes estimation of absolute distance changes that represent the range of movement in millimeters, assessment of tooth inclination and changes of treatment duration. The further approach will be dedicated to the additional evaluation of bone mineral density changes during the mesialization of the tooth in the direction to installed mini-implant. Previous studies have described methods of bone density measuring based on the Hounsfield scale that can be calculated on CBCT results. This kind of approach remains disputable and has been modified with a variety of methods. One of the trends in bone changes evaluation based on the use of the so-called superimposition principle that already has been described in the literature [34-38].

Limitations of this study are related to a relatively small study sample, but the design of the study primary was considered as a pilot to check the possibility for the implementation of the proposed OPG-analysis algorithm in orthodontic practice during tooth mesialization procedure.

The obtained results indicate that the use of orthodontic mini-implants as anchorage constructions during the mesialization of the mandibular molars contributes to a reduction in the general terms of treatment and support more prognostic movement that does not provoke significant pathological changes in the level of the alveolar crest, and minimize the risk of concomitant periodontal complications occurrence during the implementation of the rehabilitation algorithm. 


\section{Conclusion}

A proposed comprehensive approach for the evaluation of the orthodontic treatment results by means of second molar mesialization parameters allows providing simultaneous analysis of bone level changes, tooth inclination values and overall duration of treatment. Considering limitations of provided study, obtained results indicate that the use of orthodontic mini-implants as anchorage constructions during the mesialization of the mandibular second molars contributes to the reduction of treatment duration and support more prognostic movement of teeth, that does not provoke significant pathological changes in the levels of the surrounded alveolar ridge and minimize the risk of associated periodontal complication occurrence.

\section{Authors' Contributions}

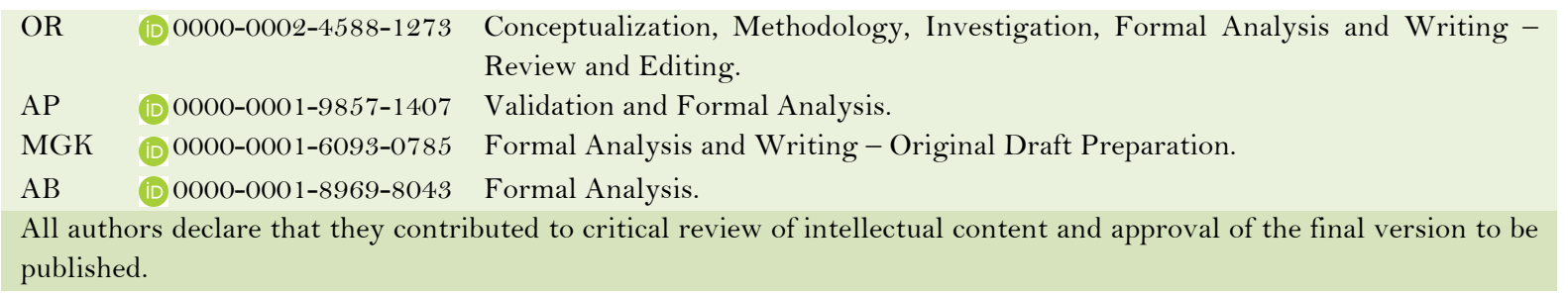

\section{Financial Support}

None.

\section{Conflict of Interest}

The authors declare no conflicts of interest.

\section{References}

[1] Samruajbenjakun B, Samansukumal S, Charoemratrote C, Leepong, N, Leethanakul C. Effects on alveolar bone changes following corticotomy-assisted molar mesialization. J Indian Orthod Soc 2018; 52(5):49-54. https://doi.org/10.1177/0974909820180508S

[2] Mehta S, Lodha S. Mandibular molar mesialization. Am J Orthod Dentofacial Orthop 2017; 152(3):292. https://doi.org/10.1016/j.ajodo.2017.05.014

[3] Arsenina OI, Kozachenko VE, Nadtochiy AG, Fomin MY, Popova NV. The mesialization of molars of the lower jaw after performance surgical manipulation with using miniscrew anchorage approach. Stomatologiia 2018; 97(4):37-41. https://doi.org/10.17116/stomat20189704137

[4] Jacobs C, Jacobs-Müller C, Luley C, Erbe C, Wehrbein H. Orthodontic space closure after first molar extraction without skeletal anchorage. Journal of Orofacial Orthopedics/Fortschritte der Kieferorthopädie 2011; 72(1):51-60. https://doi.org/10.1007/s00056-010-0007-y

[5] Cornelis M, Nyssen-Behets C. Success rates, risk factors and complications of miniplates used for orthodontic anchorage. In: Papadopoulos MA. Skeletal Anchorage in Orthodontic Treatment of Class II Malocclusion: Contemporary Applications of Orthodontic Implants, Miniscrew Implants and Mini Plates. Amsterdam: Elsevier; 2014. pp. 252-257.

[6] Klang E, Beyling F, Knösel M, Wiechmann D. Quality of occlusal outcome following space closure in cases of lower second premolar aplasia using lingual orthodontic molar mesialization without maxillary counterbalancing extraction. Head Face Med 2018; 14(1):17. https://doi.org/10.1186/s13005-018-0176-2

[7] Wilmes B, Willmann J, Stocker B, Drescher D. The Benefit System and its scope in contemporary orthodontic protocols. APOS Trends Orthod 2015; 5(5):174-80. https://doi.org/10.4103/2321-1407.163414

[8] Kuroda S, Tanaka E. Risks and complications of miniscrew anchorage in clinical orthodontics. Jpn Dent Sci Rev 2014; 50(4):79-85. https://doi.org/10.1016/j.jdsr.2014.05.001

[9] Winkler J, Göllner N, Göllner P, Pazera P, Gkantidis N. Apical root resorption due to mandibular first molar mesialization: a split-mouth study. Am J Orthod Dentofacial Orthop 2017; 151(4):708-17. https://doi.org/10.1016/j.ajodo.2016.12.005

[10] De Almeida MR, De Almeida RR, Nanda R. Biomechanics of extra-alveolar mini-implant use in the infrazygomatic crest area for asymmetrical correction of class II subdivision malocclusion. APOS Trends Orthod 2018; 8(2):110-8. https://doi.org/10.4103/apos.apos_25_18 
[11] Upadhyay M, Yadav S, Nanda R. Biomechanics of incisor retraction with mini-implant anchorage. J Orthod 2014; 41(Suppl 1):S15-23. https://doi.org/10.1179/1465313314Y.0000000114

[12] Itsuki Y, Imamura E. Multipurpose orthodontic system using palatal implants for solving extremely complex orthodontic problems. J World Fed Orthod 2017; 6(2):80-9. https://doi.org/.1016/j.ejwf.2017.04.001

[13] Wehrbein H, Göllner P. Miniscrews or palatal implants for skeletal anchorage in the maxilla: comparative aspects for decision making. World J Orthod 2008; 9(1):63-73.

[14] Wehrbein H, Göllner P. Do palatal implants remain positionally stable under orthodontic load? A clinical radiologic study. Am J Orthod Dentofacial Orthop; 136(5):695-9. https://doi.org/10.1016/j.ajodo.2007.10.050

[15] Jung BA, Kunkel M, Göllner P, Liechti T, Wehrbein H. Success rate of second-generation palatal implants: preliminary results of a prospective study. Angle Orthod 2009; 79(1):85-90. https://doi.org/10.2319/010708-8.1

[16] Jung BA, Kunkel M, Göllner P, Liechti T, Wagner W, Wehrbein H. Prognostic parameters contributing to palatal implant failures: a long-term survival analysis of 239 patients. Clin Oral Implan Res 2012; 23(6):746-50. https://doi.org/10.1111/j.1600-0501.2011.02197.x

[17] Holberg C, Winterhalder P, Holberg N, Wichelhaus A, Rudzki-Janson I. Indirect miniscrew anchorage: biomechanical loading of the dental anchorage during mandibular molar protraction - an FEM analysis. J Orofac Orthop 2014; 75(1):16-24. https://doi.org/10.1007/s00056-013-0190-8

[18] Kim SH, Choi YS, Hwang EH, Chung KR, Kook YA, Nelson G. Surgical positioning of orthodontic mini-implants with guides fabricated on models replicated with cone-beam computed tomography. Am J Orthod Dentofacial Orthop 2007; 131(4 Suppl):S82-S89. https://doi.org/10.1016/j.ajodo.2006.01.027

[19] Morea C, Dominguez GC, Wuo AV, Tortamano A. Surgical guide for optimal positioning of mini-implants. J Clin Orthod 2005; 39(5):317-21.

[20] Poggio PM, Incorvati C, Velo S, Carano A. "Safe zones": a guide for miniscrew positioning in the maxillary and mandibular arch. Angle Orthod 2006; 76(2):191-7.

[21] Kostenko YY, Goncharuk-Khomyn MY. Algorithm of analysis for panoramic X-ray images with purpose of calculation complex constant anthropometric indices of mandible and evaluation the atrophy level for alveolar part of lower jaw. Visnyk Morphologii 2013; 2(19):447-50.

[22] Honcharuk-Khomyn MY, Kostenko YY. Anthropometric calculations of proportional relationships based on digital orthopantomograms. Buk Med Herald 2013; 17(3):45-6.

[23] Forrest AS. Collection and recording of radiological information for forensic purposes. Aust Dent J 2012; 57(Suppl 1):24-32. https://doi.org/10.1111/j.1834-7819.2011.01658.x

[24] Ursi WJ, Almeida RR, Tavano O, Henriques JF. Assessment of mesiodistal axial inclination through panoramic radiography. J Clin Orthod 1990; 24(3):166-73.

[25] Katz DL, Jekel JF. Jekel's Epidemiology, Biostatistics, Preventive Medicine, and Public Health. 4.th. Amsterdam: Elsevier; 2014.

[26] Altman DG, Gardner MJ. Statistics in medicine: calculating confidence intervals for regression and correlation. Br Med J 1998; 296(6631):1238. https://doi.org/10.1136/bmj.296.6631.1238

[27] Altman DG, Bland JM. Measurement in medicine: the analysis of method comparison studies. Statistician 1983; 32:307-17. https://doi.org/10.2307/2987937

[28] Kaipatur N, Wu Y, Adeeb S, Stevenson T, Major P, Doschak M. A novel rat model of orthodontic tooth movement using temporary skeletal anchorage devices: 3D finite element analysis and in vivo validation. Int J Dent 2014; 2014: 917535. https://doi.org/10.1155/2014/917535

[29] Park JH, Chae JM, Bay RC, Kim MJ, Lee KY, Chang NY. Evaluation of factors influencing the success rate of orthodontic microimplants using panoramic radiographs. Korean J Orthod 2018; 48(1):30-8. https://doi.org/10.4041/kjod.2018.48.1.30

[30] Becker K, Wilmes B, Grandjean C, Vasudavan S, Drescher D. Skeletally anchored mesialization of molars using digitized casts and two surface-matching approaches. J Orofac Orthop 2018; 79(1):11-8. https://doi.org/10.1007/s00056-017-0108-y

[31] Rusyn V, Goncharuk-Khomyn M. Alternative approach for the registration of peri-implant bone level changes at the remote rehabilitation period. Morphologia 2016;10(2):77-84.

[32] Devlin H, Yuan J. Object position and image magnification in dental panoramic radiography: a theoretical analysis. Dentomaxillofac Radiol 2013; 42(1):29951683. https://doi.org/10.1259/dmfr/29951683

[33] Yepes JF, Powers E, Downey T, Eckert GJ, Tang Q, Vinson L, Maupomé G. Prescription of panoramic radiographs in children: a health services assessment of current guidelines. Pediatr Dent 2017; 39(4):289-96.

[34] Villarinho EA, Correia A, Vigo A, Ramos NV, Pires VM, Arai SR. Volumetric bone measurement around dental implants using 3D image superimposition: a methodological and clinical pilot study. Int J Prosthodont 2018; 31(1):23-30. https://doi.org/10.11607/ijp.5366

[35] Correia A, Villarinho E, Vigo A, Ramos NV, Vaz M, Shinkai R. Volumetric bone changes around dental implants, the use of 3D image superimposition. Clin Oral Implan Res 2017; 28(Suppl 14):245. https://doi.org/10.1111/clr.244_13042 
[36] Goncharuk-Khomyn M, Andrii K. Evaluation of peri-implant bone reduction levels from superimposition perspective: pilot study among Ukrainian implantology practice. Pesqui Bras Odontopediatria Clin Integr 2018; 18(1):3856. https://doi.org/10.4034/PBOCI.2018.181.10

[37] Bienz SP, Jung RE, Sapata VM, Hämmerle CH, Hüsler J, Thoma DS. Volumetric changes and peri-implant health at implant sites with or without soft tissue grafting in the esthetic zone: a retrospective case-control study with a 5 -year follow-up. Clin Oral Implan Res 2017; 28(11):1459-65. https://doi.org/10.1111/clr.13013

[38] Sapata VM, Sanz-Martín I, Hämmerle CH, Cesar Neto JB, Jung RE, Thoma DS. Profilometric changes of periimplant tissues over 5 years: A randomized controlled trial comparing a one-and two-piece implant system. Clin Oral Implan Res 2018; 29(8):864-72. https://doi.org/10.1111/clr.13308 